\title{
Patient Satisfaction and Its Relation to Perceived Visit Duration With a Hand Surgeon
}

\section{Citation}

Parrish, Raymond C. 2018. Patient Satisfaction and Its Relation to Perceived Visit Duration With a Hand Surgeon. Doctoral dissertation, Harvard Medical School.

\section{Permanent link}

http://nrs.harvard.edu/urn-3:HUL.InstRepos:41973468

\section{Terms of Use}

This article was downloaded from Harvard University's DASH repository, and is made available under the terms and conditions applicable to Other Posted Material, as set forth at http:// nrs.harvard.edu/urn-3:HUL.InstRepos:dash.current.terms-of-use\#LAA

\section{Share Your Story}

The Harvard community has made this article openly available.

Please share how this access benefits you. Submit a story.

\section{Accessibility}




\section{Scholarly Report}

Date: 10 January 2018

Student Name: Raymond Charles Parrish II, BS

Scholarly Report Title: Patient Satisfaction and its Relation to Perceived Visit Duration With a Hand Surgeon

\section{Mentor Names and Affiliations:}

Neal C. Chen, MD, Dept of Orthopaedic Surgery, Massachusetts General Hospital;

David C. Ring, MD, PhD, Dept of Surgery \& Perioperative Care, University of Texas at Austin

\section{Collaborators, with Affiliations:}

Mariano E. Menendez, MD, PhD, Dept of Orthopaedic Surgery, Tufts University;

Chaitanya S. Mudgal, MD, Dept of Orthopaedic Surgery, Massachusetts General Hospital;

Jesse B. Jupiter, MD, Dept of Orthopaedic Surgery, Massachusetts General Hospital 


\section{Abstract \\ TITLE: Patient Satisfaction and its Relation to Perceived Visit Duration With a Hand Surgeon}

Raymond C. Parrish II, Mariano E. Menendez, Chaitanya S. Mudgal, Jesse B. Jupiter, Neal C. Chen, David C. Ring

Purpose: To determine whether patient perception of time spent with a hand surgeon relates to patient satisfaction after a single new patient office visit.

Methods: Prior to each visit, 112 consecutive new patients predicted how much time they expected to spend with the surgeon. Following the visit, patients were asked to estimate the time spent with the surgeon, indicate whether the surgeon appeared rushed, and rate their overall satisfaction with the surgeon. Wait time and actual visit duration were measured. Patients also completed a sociodemographic survey, the Consultation and Relational Empathy (CARE) Measure, the Newest Vital Sign (NVS) health literacy test, and 3 Patient-Reported Outcomes Measurement Information System (PROMIS)-based questionnaires: Upper-Extremity Function, Pain Interference, and Depression. Multivariable logistic and linear regression models were used to determine predictors of patient satisfaction, patient-perceived surgeon rush, and high previsit expectations of visit duration.

Results: Patient satisfaction was not associated with perceived visit duration, but did correlate strongly with patient-rated surgeon empathy and symptoms of depression. Neither visit duration nor previsit expectations of visit length were determinants of patient-perceived surgeon rush; only surgeon empathy was associated. Less educated patients anticipated needing more time with the surgeon.

Conclusions: Patient satisfaction with the surgeon and with the time spent during the office visit was primarily linked to surgeon empathy rather than to visit duration or 
previsit expectation of visit length. Efforts to make hand surgery office visits more patient centered should focus on improving dialogue quality, and not necessarily on making visits longer.

Type of study/level of evidence: Prognostic II.

Key words: Doctor rush, empathy, expectations, patient satisfaction, visit duration. 


\section{Student Role}

I participated in the conception of the hypotheses tested herein as well as study design in conjunction with Dr. Menendez, Dr. Ring, and Dr. Chen. I was solely responsible for enrolling the patients, interviewing the patients, recording all study data, performing statistical analysis on said data, interpreting the results of the statistical computations, creating all tables and figures, and primary writing of the manuscript. Dr. Menendez directly supervised and assisted in my work performing the statistical analysis and initial interpretation of results. Dr. Menendez, Dr. Mudgal, Dr. Jupiter, Dr. Chen, Dr. Ring, and I all participated in the editing and revision process for the manuscript.

\section{Publication Information}

Link: https://www.ncbi.nlm.nih.gov/pubmed/26718069

\section{Citation:}

Parrish RC II, Menendez ME, Mudgal CS, Jupiter JB, Chen NC, Ring DC. Patient satisfaction and its relation to perceived visit duration with a hand surgeon. Journal of Hand Surgery [American]. 2016 Feb;41(2):257-62.e1-4. 


\title{
Patient Satisfaction and its Relation to Perceived Visit Duration. With a Hand Surgeon
}

\author{
Raymond C. Parrish II, BS, ${ }^{*}$ Mariano E. Menendez, MD, ${ }^{*}$ Chaitanya S. Mudgal, MD,* \\ Jesse B. Jupiter, MD, ${ }^{*}$ Neal C. Chen, MD, ${ }^{*}$ David Ring, MD, $\mathrm{PhD}^{*}$
}

Purpose To determine whether patient perception of time spent with a hand surgeon relates to patient satisfaction after a single new-patient office visit.

Methods Prior to each visit, 112 consecutive new patients predicted how much time they expected to spend with the surgeon. Following the visit, patients were asked to estimate the time spent with the surgeon, indicate whether the surgeon appeared rushed, and rate their overall satisfaction with the surgeon. Wait time and actual visit duration were measured. Patients also completed a sociodemographic survey, the Consultation and Relational Empathy Measure, the Newest Vital Sign Health Literacy test, and 3 Patient-Reported Outcomes Measurement Information System-based questionnaires: Upper Extremity Function, Pain Interference, and Depression. Multivariable logistic and linear regression models were used to determine predictors of patient satisfaction, patient-perceived surgeon rush, and high previsit expectations of visit duration.

Results Patient satisfaction was not associated with perceived visit duration but did correlate strongly with patient-rated surgeon empathy and symptoms of depression. Neither visit duration nor previsit expectations of visit length were determinants of patient-perceived surgeon rush. Only surgeon empathy was associated. Less-educated patients anticipated needing more time with the surgeon.

Conclusions Patient satisfaction with the surgeon and with the time spent during the office visit was primarily linked to surgeon empathy rather than to visit duration or previsit expectation of visit length. Efforts to make hand surgery office visits more patient-centered should focus on improving dialogue quality, and not necessarily on making visits longer. ( $J$ Hand Surg Am. 2016;41(2):257-262. Copyright ( 2016 by the American Society for Surgery of the Hand. All rights reserved.)

Type of study/level of evidence Prognostic II.

Key words Doctor rush, empathy, expectations, patient satisfaction, visit duration.

From the *Department of Orthopaedic Surgery, Massachusetts General Hospital, Harvard Medical School, Boston, MA.

Received for publication August 25, 2015; accepted in revised form November 16, 2015. No benefits in any form have been received or will be received related directly or indirectly to the subject of this article.

Corresponding author: David Ring, MD, PhD, Department of Orthopaedic Surgery, Massachusetts General Hospital, 55 Fruit St., Yawkey Center, Suite 2100, Boston, MA 02114; e-mail: dring@partners.org.

0363-5023/16/4102-0016\$36.00/0 http://dx.doi.org/10.1016/j.jhsa.2015.11.015
0 ATIENT SATISFACTION IS AN INCREASINGLY emphasized measure of patient-centered care and an important component of reimbursement programs. ${ }^{1-3}$ Time management in outpatient office visits is often viewed as one determinant of patient satisfaction. Primary care patients are generally more satisfied with longer visits, ${ }^{4-8}$ although no such link has been found in ambulatory orthopedics. ${ }^{9,10}$

Research on the relationship between visit duration and satisfaction has largely focused on actual visit 
duration, ${ }^{4-7,9,10}$ whereas common provider performance evaluations ${ }^{11-13}$ and physician Web site ratings ${ }^{14,15}$ rely instead on patient-perceived visit duration as a component of patient satisfaction with their provider. Patients' perceptions of sufficient time spent by their providers may take the form of a discrete perceived visit duration or perceived provider rush in general. ${ }^{8}$

We undertook this study to determine whether patient perception of time spent with a hand surgeon correlated with patient satisfaction after a single newpatient office visit. Our primary null hypothesis was that satisfaction is not associated with patient-perceived visit duration. We also analyzed associations of other patient and visit characteristics_-including actual visit duration-with satisfaction. In addition, we sought to identify correlates of patient-perceived surgeon rush and high expectations for time needed with the surgeon.

\section{MATERIALS AND METHODS}

Design

Upon approval of our institutional review board, 119 new patients visiting the ambulatory offices of 5 attending orthopedic hand surgeons, 4 of whom are authors of this article (C.S.M., J.B.J., N.C.C., D.R.), were invited to participate in this prospective crosssectional study. Inclusion criteria comprised patients who were 18 years old or older, fluent and literate in English, and capable of giving informed consent. Patients who had previously seen the attending surgeon they had an appointment with (follow-up patients) were excluded. Patients were consecutively enrolled 5 days per week for 4 weeks. Seven $(6 \%)$ patients declined participation, leaving a cohort of 112 individuals.

Prior to each visit, a research fellow (R.C.P.) not involved with clinical care asked how much time the consented patients expected their surgeon (attending physician) to spend with them. Following the visit with the surgeon, the patients were asked to rate their satisfaction with the surgeon they saw, estimate how long they waited to see the surgeon after checking in, estimate how long the surgeon spent with them in the room, and assess whether or not they felt the surgeon was rushed. We also asked patients to complete a sociodemographic survey (including age, sex, race/ethnicity, level of education, insurance status, work status, and marital status), the Newest Vital Sign (NVS) Health Literacy test, ${ }^{16} 3$ Patient-Reported Outcomes Measurement Information System (PROMIS)-based computerized adaptive questionnaires (Upper Extremity Function, ${ }^{17}$ Pain Interference, $^{18,19}$ and Depression ${ }^{20,21}$ ), and the Consultation and Relational Empathy Measure that assesses the patient's perception of the surgeon's demonstrated level of empathy in the visit. ${ }^{19,22}$ We also measured the waiting time to see the surgeon after checking in, the actual duration of the visit, and whether or not a resident or fellow saw the patient before the attending surgeon did. The patient tracking system in the clinic was used to measure waiting time, and the research fellow measured actual visit duration with a stopwatch from outside the patient rooms.

All questionnaires and surveys were completed by the patient on a laptop computer, except the NVS Health Literacy test, which was administered orally in accordance with its guidelines. ${ }^{16}$ Each patient's chart was reviewed following the visit for diagnosis (traumatic or nontraumatic) and visit type (first or second opinion). Although the surgeons were aware of the existence of this study, they were not aware which patients were enrolled in it.

\section{Variables}

Patient satisfaction, the primary outcome variable, was measured after the visit by asking patients to rate their overall satisfaction with the surgeon on a scale of 0 to 10 (with 0 representing "worst doctor possible" and 10 representing "best doctor possible"). This item was derived from the Clinician and Group-Consumer Assessment of Healthcare Providers and Systems Adult Visit Survey. ${ }^{10,13,23}$ Patients were considered satisfied if they answered 9 or 10 , consistent with previously described interpretations of this satisfaction item. $^{2}$ Although it is unusual to dichotomize a relatively continuous measure, the distribution is usually highly skewed toward satisfaction-in other words, the item dichotomizes itself with a relatively small group of patients with satisfaction of 8 or less.

Explanatory variables measured include the aforementioned visit characteristics, patient perceptions of visit characteristics, and patient sociodemographic information.

Three PROMIS computerized adaptive tests, which involve a dynamic set of questions based on responses to prior questions, ${ }^{24}$ were used to assess aspects of the patients' physical and mental health. Specifically, these tests use item response theory models, a psychometric method wherein certain scores are associated with answers to each question. A score corresponding to the answer provided by the respondent then allows the computer software to dynamically select subsequent questions that will provide the most additional information. Patient-Reported Outcomes Measurement Information System tests also employ T-scores with a mean of 50 that corresponds to the mean of the U.S general population. ${ }^{25}$ The PROMIS Pain Interference questionnaire quantifies how much pain has 
potentially prevented participation in or enjoyment of normal physical and social activities over the week prior to administration. ${ }^{18}$ The PROMIS Upper Extremity Function questionnaire identifies the extent of arm and hand disability by asking questions about the degree of difficulty a patient faces when doing daily tasks like dressing, holding a plate of food, or using tools. ${ }^{17}$ The PROMIS Depression questionnaire assesses depression status by asking about feelings of self-worth, sadness, and other depressive symptoms that may have occurred in the last week. ${ }^{20}$

Patient health literacy was quantified using the NVS Health Literacy survey, a validated 6-item instrument with scores ranging from 0 to 6 in which higher scores indicate greater health literacy. This test uses questions about the nutritional content and safety of a hypothetical container of ice cream (when patients are presented with a nutrition label thereof) as a proxy measurement of health literacy and numeracy. ${ }^{16,26,27}$

Patient-rated surgeon empathy was evaluated using the Consultation and Relational Empathy Measure, an independently validated test for perception of empathic behavior that asks 10 questions such as "How was the doctor at... (1) Making you feel at ease?; (2) Letting you tell your "story"?; (3) Really listening?" Each of the 10 questions is answered on a 5-point Likert scale, with responses ranging from 1 (poor) to 5 (excellent). The scores for the 10 items are then summed, yielding a minimum score of 10 and a maximum score of 50, where higher scores indicate greater empathy.

\section{Statistical analysis}

An a priori power calculation determined that a minimal sample size of 112 patients was required to have $90 \%$ statistical power (with $\alpha=0.05$ ) to detect a 0.30 correlation between patient-perceived visit duration and patient satisfaction.

The potential association between each of the explanatory variables and patient satisfaction was analyzed using a Pearson chi-square test (for categorical variables) or a Fisher exact test (for categorical variables of cell size $<5$ ), and an independent samples $t$ test (for continuous variables). For secondary analyses, patient-perceived surgeon rush and patient previsit expectation of visit duration were used as secondary outcome variables and potential associations were analyzed in a similar fashion. Patient previsit expectation of visit duration was considered high if it was 20 minutes or longer.

For the primary and secondary outcome variables, a multivariable logistic regression was run to determine factors independently associated with each outcome variable. All factors that showed a statistically significant association with the outcome variable of interest in bivariate analysis were simultaneously included in the multivariable model. Results from the logistic model were reported as odds ratios (OR) with $95 \%$ confidence intervals (CI). For patient satisfaction, a multiple linear regression was also run to determine the degree to which each included explanatory variable accounted for the variation observed in patient satisfaction (partial $\mathrm{R}^{2}$ ).

\section{Patient characteristics}

The 112 patients composing our sample cohort included $60(54 \%)$ males and $52(46 \%)$ females with a mean \pm SD age of $49 \pm 17$ years. Of these patients, $72 \%$ were white, $81 \%$ had private insurance, $78 \%$ were working, and $62 \%$ were married. Patients had an average of $16 \pm 3$ years of education. The mean expected visit duration was $16 \pm 910$ minutes. Patients waited an average of $29 \pm 16$ minutes and had a mean actual visit duration of $10 \pm 6$ minutes. Five percent of patients coming in to the office were there for a second opinion, and $46 \%$ of patients were there as the result of an injury (Appendix A; available on the Journal's Web site at www.jhandsurg.org).

\section{RESULTS}

\section{Patient satisfaction}

Patient satisfaction was not associated with actual visit duration $(\mathrm{r}=-0.010 ; P=.92)$ or patient-perceived visit duration $(\mathrm{r}=0.12 ; P=.21$; Fig. 1$)$. After controlling for potential confounding effects in multivariable logistic regression, factors independently associated with patient dissatisfaction included greater symptoms of depression (OR 1.1; 95\% CI 1.0-1.2; $P=.009)$ and lower patient-rated surgeon empathy (OR 0.83; 95\% CI 0.75-0.90; $P<.001$; Table 1 ). Using multiple linear regression to account for any confounding, patient-rated surgeon empathy accounted for $34 \%$ of the variation in satisfaction $(P<.001)$ with symptoms of depression accounting for much less $(2.6 \% ; P=.008)$. Patient health literacy, previsit expectation of visit duration, actual wait time, and patient-perceived wait time were not associated with patient satisfaction (Appendix B; available on the Journal's Web site at www.jhandsurg.org).

\section{Patient-perceived surgeon rush}

Overall, $11 \%$ of patients felt the surgeon rushed. These patients had the same actual visit duration and previsit expectations of visit duration as patients who did not perceive the surgeon as rushed (Fig. 2; Appendix B; available on the Journal's Web site at www.jhandsurg. org). Only patient-rated surgeon empathy was found to 


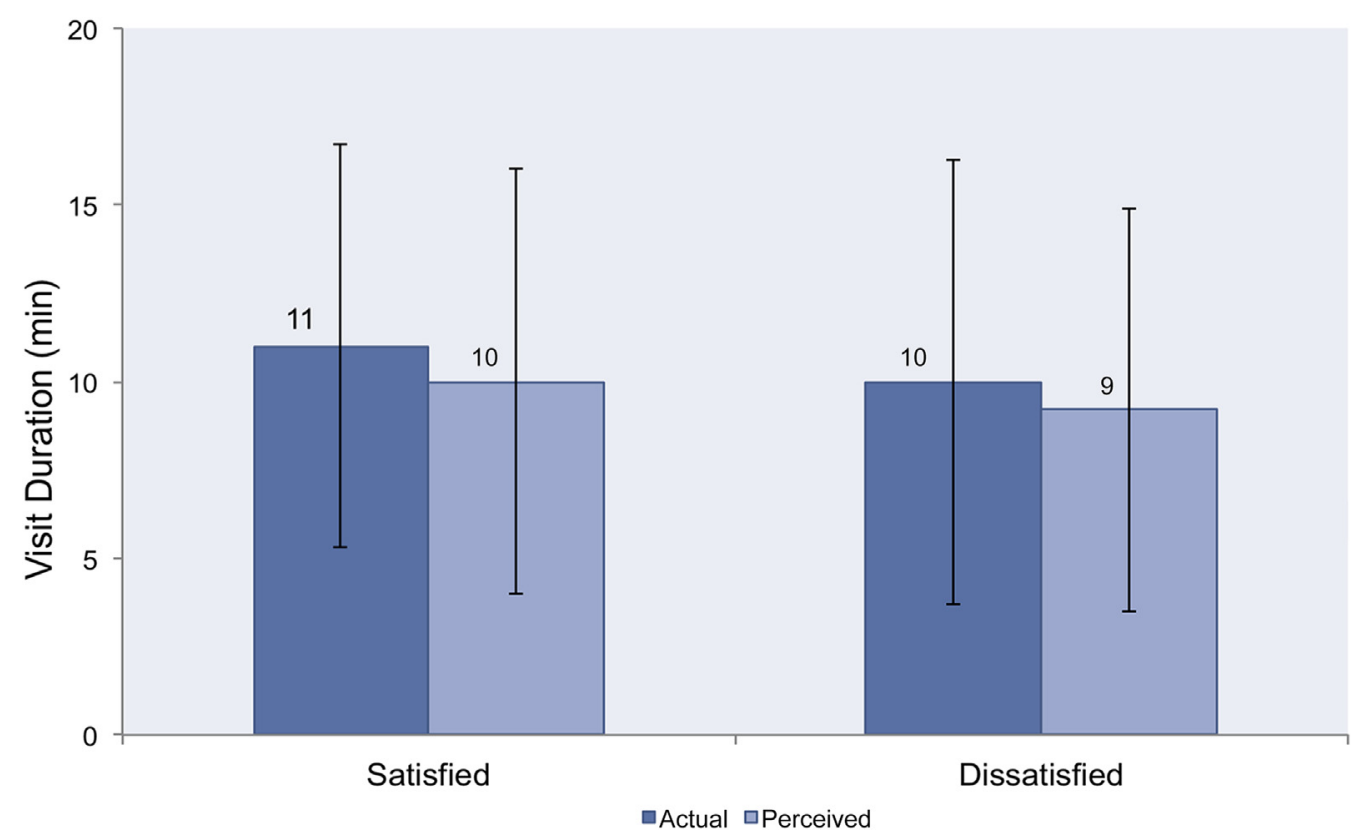

FIGURE 1: Actual and patient-perceived visit duration for satisfied versus dissatisfied patients.

\section{TABLE 1. Multivariable Logistic Regression: Factors Associated With Patient Dissatisfaction With Surgeon*}

\begin{tabular}{|c|c|c|c|c|}
\hline \multirow[b]{2}{*}{ Predictor } & \multirow[b]{2}{*}{ OR } & \multicolumn{2}{|c|}{$95 \% \mathrm{CI}$} & \multirow[b]{2}{*}{$P$} \\
\hline & & Lower & Upper & \\
\hline Age, per $10-y$ increase & 0.68 & 0.41 & 1.1 & .12 \\
\hline Unemployed (reference: employed) & 0.58 & 0.085 & 4.0 & .58 \\
\hline Unmarried (reference: married) & 0.80 & 0.20 & 3.2 & .76 \\
\hline PROMIS Depression, per 1-unit increase & 1.1 & 1.0 & 1.2 & $.009+$ \\
\hline Attending surgeon A (reference: all others) & 2.2 & 0.62 & 7.8 & .23 \\
\hline Patient perceived surgeon rush (reference: no) & 3.8 & 0.55 & 26 & .18 \\
\hline CARE Measure, per 1-unit increase & 0.83 & 0.75 & 0.90 & $<.001+$ \\
\hline
\end{tabular}

be independently associated with perceived surgeon rush (OR 0.86; 95\% CI 0.79-0.94; $P=.001$ ) in multivariable regression modeling (Appendix $C$; available on the Journal's Web site at www.jhandsurg. org). Although patients with traumatic conditions more frequently felt the surgeon rushed than patients with nontraumatic conditions, diagnosis was not retained as an independent predictor of perceived surgeon rush in multivariable analysis.

\section{Patient previsit expectation of visit duration}

Although several factors such as age, race/ethnicity, years of education, PROMIS Pain Interference, PROMIS Upper Extremity Function, and PROMIS Depression were associated with patient previsit expectation of visit duration in bivariate analysis, years of education was the only factor found to be independently associated with a high patient previsit expectation of visit duration (OR 0.82 ; 95\% CI $0.67-0.99 ; P=.04$ ) in a multivariable logistic regression.

\section{DISCUSSION}

Patient-perceived visit duration was not significantly associated with patient satisfaction. Our results suggest that, if a relationship between perception of longer visits and patient satisfaction exists in hand surgery, it is likely to be less concerning than that previously reported in the primary care setting. ${ }^{8,28}$ In addition, no association was found between actual visit duration and patient satisfaction, corroborating prior results 


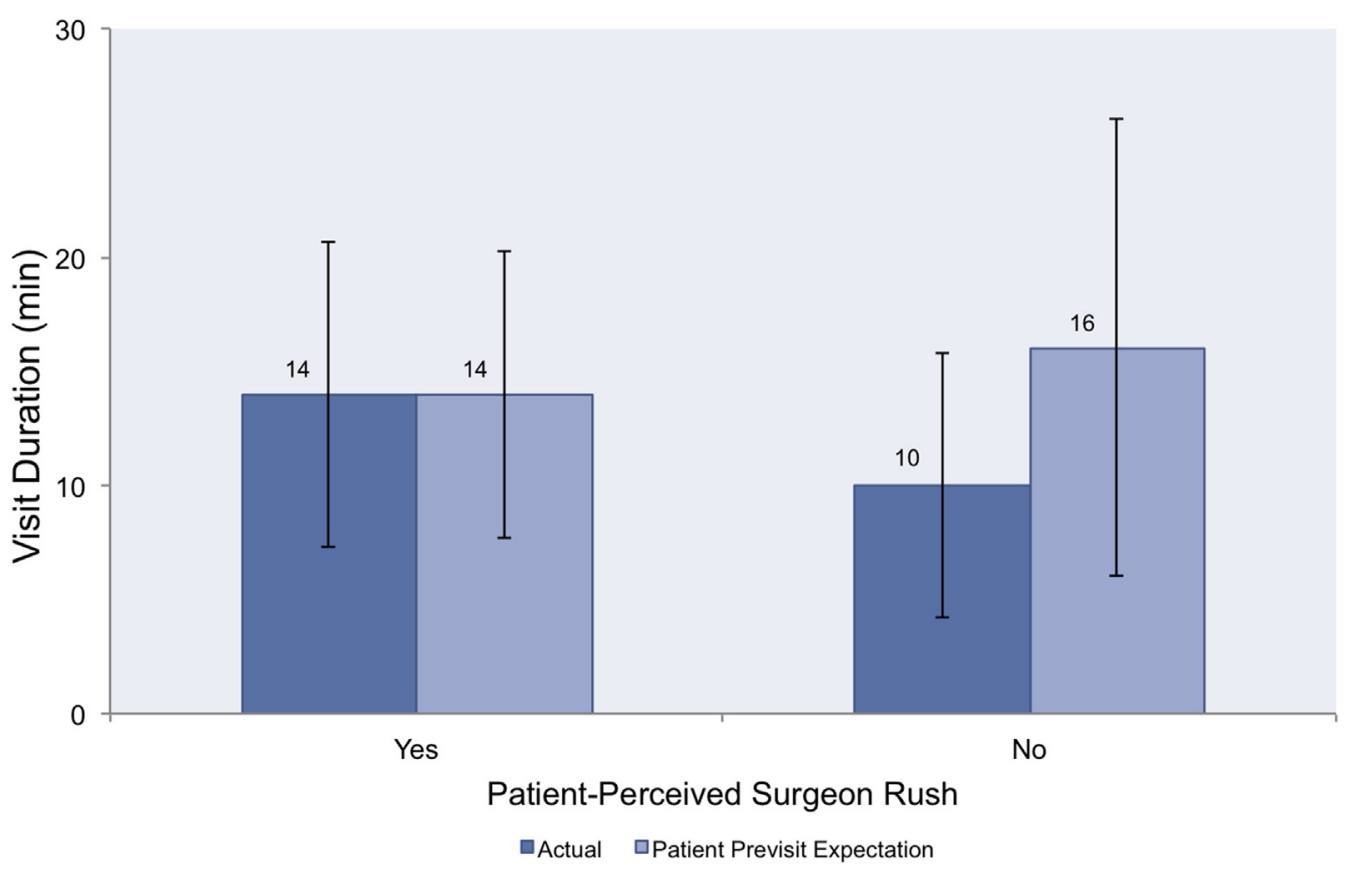

FIGURE 2: Actual and patient previsit expectation of visit duration for patients who perceived the surgeon to be rushed versus unrushed.

from other specialty-care studies. ${ }^{9,10}$ Patient-rated surgeon empathy was the strongest driver of patient satisfaction, a finding that is consistent with a recent study in hand surgery patients. ${ }^{10}$ Depressive symptoms also accounted for some of the variation in satisfaction, which is in agreement with previous orthopedic studies and suggests that emotional health may influence the patient experience. ${ }^{29-31}$

Patients indicated that hand surgeons appeared rushed in $11 \%$ of encounters, an incidence that is higher than the $3 \%$ reported by primary care patients. ${ }^{8}$ This is concerning for specialty care given that provider evaluation metrics explicitly ask if the provider spent sufficient time with the patient (ie, was not rushed). ${ }^{11}$ Our data suggest that neither visit length nor previsit expectations of visit duration were determinants of patient satisfaction regarding time spent with the hand surgeon. The finding that lower surgeon empathy was predictive of patient-perceived surgeon rush provides further evidence of the importance of effective interpersonal communication skills in the outpatient office setting and suggests that hand surgeons should focus on the quality rather than the quantity of time spent with patients. Patient-rated surgeon empathy may not correlate precisely with truly empathetic communication, but optimal communication strategies are important. Patients decide whether a surgeon is interested in their well-being. Methods of communicating interest include spending less time on technical information (limit the information to scripted, brief key points that are easy to digest and meaningful to the patient) and briefly chatting about nonmedical topics. ${ }^{5}$

We found that less-educated patients anticipated needing more time with the hand surgeon. The reasons for this merit further research. Previsit expectations have also been found to be unassociated with patient satisfaction in primary care, ${ }^{32}$ although the relationship between expectations and satisfaction may ultimately vary by expectation type (eg, pain relief, improvement in function). ${ }^{33,34}$ We examined only previsit expectation of visit duration, so it is possible that other expectations may play a role in satisfaction for hand surgery office visits.

We acknowledge some limitations to our study. The data may have limited generalizability to other regions, populations, and practice settings in that all patients were outpatients visiting fellowship-trained hand surgeons at a single urban academic hospital in the Northeastern United States. Another limitation is that differences in presenting condition and visit outcome (ie, diagnosis) may have affected the way in which patients reported their perceptions of the surgeon and visit ${ }^{35}$; however, this does provide a representative sample of the conditions traditionally presenting to an outpatient hand surgery office. In addition, most patients (75 of 112) were seen by 1 surgeon, meaning that we cannot thoroughly examine physician characteristics associated with our primary and secondary outcome measures. We also enrolled only new patients, and the relationship between patient satisfaction and visit duration may change for 
subsequent visits (eg, follow-up or postoperative care). ${ }^{8}$ Furthermore, we did not account for surgeon punctuality and time of day, both of which may influence patient satisfaction. Ideally, it would have been better to standardize time of day. Finally, the attending surgeons were aware of the existence of this study, which may have caused them to subconsciously alter their behavior to improve patient satisfaction. The notion that people may act differently as a result of being observed is called the Hawthorne effect. ${ }^{36}$

Our study demonstrated that patient satisfaction with the surgeon and with the time spent during an office visit (perceived surgeon rush) was primarily determined by surgeon empathy rather than visit duration or previsit expectation of visit duration. This information highlights the importance of empathy as not only a direct driver of overall visit satisfaction but also as a determinant of the perception of sufficient time spent by the surgeon. Efforts to make hand surgery office visits more patient-centered should primarily focus on improving dialogue quality, and not necessarily on making visits longer.

\section{REFERENCES}

1. Banka G, Edgington S, Kyulo N, et al. Improving patient satisfaction through physician education, feedback, and incentives. J Hosp Med. 2015;10(8):497-502.

2. Jha AK, Orav EJ, Zheng J, Epstein AM. Patients' perception of hospital care in the United States. N Engl J Med. 2008;359(18): 1921-1931.

3. Waljee JF, Curtin C. Quality assessment in hand surgery. Hand Clin. 2014;30(3):329-334, vi.

4. Geraghty EM, Franks P, Kravitz RL. Primary care visit length, quality, and satisfaction for standardized patients with depression. J Gen Intern Med. 2007;22(12):1641-1647.

5. Gross DA, Zyzanski SJ, Borawski EA, Cebul RD, Stange KC. Patient satisfaction with time spent with their physician. J Fam Pract. 1998;47(2):133-137.

6. Halfon N, Stevens GD, Larson K, Olson LM. Duration of a wellchild visit: association with content, family-centeredness, and satisfaction. Pediatrics. 2011;128(4):657-664.

7. Hughes D. Consultation length and outcome in two group general practices. J R Coll Gen Pract. 1983;33(248):143-147.

8. Lin CT, Albertson GA, Schilling LM, et al. Is patients' perception of time spent with the physician a determinant of ambulatory patient satisfaction? Arch Intern Med. 2001;161(11):1437-1442.

9. Teunis T, Thornton ER, Jayakumar P, Ring D. Time seeing a hand surgeon is not associated with patient satisfaction. Clin Orthop Relat Res. 2015;473(7):2362-2368.

10. Menendez ME, Chen NC, Mudgal CS, Jupiter JB, Ring D. Physician empathy as a driver of hand surgery patient satisfaction. J Hand Surg Am. 2015;40(9):1860-1865.e2.

11. Agency for Healthcare Research and Quality. Available at: http:// www.cahps.ahrq.gov/clinician_group. Accessed July 25, 2015.

12. Hageman MG, Ring DC, Gregory PJ, Rubash HE, Harmon L. Do 360-degree feedback survey results relate to patient satisfaction measures? Clin Orthop Relat Res. 2015;473(5):1590-1597.

13. Dyer N, Sorra JS, Smith SA, Cleary PD, Hays RD. Psychometric properties of the Consumer Assessment of Healthcare Providers and Systems (CAHPS(R)) Clinician and Group Adult Visit Survey. Med Care. 2012;50(Suppl):S28-S34.
14. Healthgrades. Available at: http://www.healthgrades.com/. Accessed July 17, 2015.

15. DrScore.com. Available at: http://www.drscore.com/?dspGMCimage=1. Accessed July 28, 2015.

16. Weiss BD, Mays MZ, Martz W, et al. Quick assessment of literacy in primary care: the newest vital sign. Ann Fam Med. 2005;3(6):514-522.

17. Hays RD, Spritzer KL, Amtmann D, et al. Upper-extremity and mobility subdomains from the Patient-Reported Outcomes Measurement Information System (PROMIS) adult physical functioning item bank. Arch Phys Med Rehabil. 2013;94(11):2291-2296.

18. Amtmann D, Cook KF, Jensen MP, et al. Development of a PROMIS item bank to measure pain interference. Pain. 2010;150(1):173-182.

19. Mercer SW, Maxwell M, Heaney D, Watt GC. The Consultation and Relational Empathy (CARE) measure: development and preliminary validation and reliability of an empathy-based consultation process measure. Fam Pract. 2004;21(6):699-705.

20. Pilkonis PA, Choi SW, Reise SP, et al. Item banks for measuring emotional distress from the Patient-Reported Outcomes Measurement Information System (PROMIS(R)): depression, anxiety, and anger. Assessment. 2011;18(3):263-283.

21. Menendez ME, Bot AG, Hageman MG, Neuhaus V, Mudgal CS, Ring D. Computerized adaptive testing of psychological factors: relation to upper-extremity disability. J Bone Joint Surg Am. 2013;95(20):e149.

22. Mercer SW, McConnachie A, Maxwell M, Heaney D, Watt GC. Relevance and practical use of the Consultation and Relational Empathy (CARE) Measure in general practice. Fam Pract. 2005;22(3):328-334.

23. Crofton C, Lubalin JS, Darby C. Consumer Assessment of Health Plans Study (CAHPS). Foreword. Med Care. 1999;37(3 Suppl): MS1-MS9.

24. Chakravarty EF, Bjorner JB, Fries JF. Improving patient reported outcomes using item response theory and computerized adaptive testing. J Rheumatol. 2007;34(6):1426-1431.

25. NIH Promis. Available at: http://www.nihpromis.org/faqs. Accessed Sept. 25, 2015.

26. Morrison AK, Chanmugathas R, Schapira MM, Gorelick MH, Hoffmann RG, Brousseau DC. Caregiver low health literacy and nonurgent use of the pediatric emergency department for febrile illness. Acad Pediatr. 2014;14(5):505-509.

27. Menendez ME, Mudgal CS, Jupiter JB, Ring D. Health literacy in hand surgery patients: a cross-sectional survey. J Hand Surg Am. 2015;40(4):798-804.e792.

28. Anderson RT, Camacho FT, Balkrishnan R. Willing to wait?: the influence of patient wait time on satisfaction with primary care. $B M C$ Health Serv Res. 2007;7:31.

29. Knutsen EJ, Paryavi E, Castillo RC, O'Toole RV. Is satisfaction among orthopaedic trauma patients predicted by depression and activation levels? J Orthop Trauma. 2015;29(5):e183-e187.

30. Vranceanu AM, Ring D. Factors associated with patient satisfaction. J Hand Surg Am. 2011;36(9):1504-1508.

31. Abtahi AM, Brodke DS, Lawrence BD, Zhang C, Spiker WR. Association between patient-reported measures of psychological distress and patient satisfaction scores after spine surgery. J Bone Joint Surg Am. 2015;97(10):824-828.

32. Bowling A, Rowe G, McKee M. Patients' experiences of their healthcare in relation to their expectations and satisfaction: a population survey. J R Soc Med. 2013;106(4):143-149.

33. Iversen MD, Daltroy LH, Fossel AH, Katz JN. The prognostic importance of patient pre-operative expectations of surgery for lumbar spinal stenosis. Patient Educ Couns. 1998;34(2):169-178.

34. Soroceanu A, Ching A, Abdu W, McGuire K. Relationship between preoperative expectations, satisfaction, and functional outcomes in patients undergoing lumbar and cervical spine surgery: a multicenter study. Spine (Phila Pa 1976). 2012;37(2):E103-E108.

35. Hirukawa M, Ohira Y, Uehara T, et al. Satisfaction of patients and physicians with outpatient consultations at a university hospital. Intern Med. 2015;54(12):1499-1504.

36. Sedgwick P, Greenwood N. Understanding the Hawthorne effect. BMJ. 2015;351:h4672. 
APPENDIX A. Characteristics of Study Sample (Outcome: Patient Satisfaction)

\begin{tabular}{|c|c|c|c|c|}
\hline \multirow[b]{2}{*}{ Parameter } & \multirow[b]{2}{*}{ All Patients } & \multicolumn{2}{|c|}{ Patient Satisfaction With Surgeon } & \multirow[b]{2}{*}{$P$} \\
\hline & & Satisfied $(9-10)$ & Dissatisfied $(\leq 8)$ & \\
\hline Total ${ }^{*}$ & 112 & $75(67)$ & $37(33)$ & \\
\hline Age $(y)^{\dagger}$ & $49 \pm 17(21-88)$ & $53 \pm 16(21-88)$ & $40 \pm 14(21-68)$ & $<.001$ \\
\hline \multicolumn{5}{|l|}{ Sex* } \\
\hline Female & 52 & $34(65)$ & $18(35)$ & \multirow{2}{*}{.74} \\
\hline Male & 60 & $41(68)$ & $19(32)$ & \\
\hline \multicolumn{5}{|l|}{ Race/ethnicity* } \\
\hline White & 81 & $54(67)$ & $27(33)$ & \multirow{2}{*}{.91} \\
\hline Nonwhite & 31 & $21(68)$ & $10(32)$ & \\
\hline Education $(\mathrm{y})^{\dagger}$ & $16 \pm 2.9(9-27)$ & $15 \pm 2.8(9-27)$ & $16 \pm 2.9(12-24)$ & .53 \\
\hline \multicolumn{5}{|l|}{ Insurance status* } \\
\hline Medicare & 15 & $12(80)$ & $3(20)$ & \multirow{5}{*}{.44} \\
\hline Medicaid & 3 & $1(33)$ & $2(67)$ & \\
\hline Private & 91 & $60(66)$ & $31(34)$ & \\
\hline Uninsured & 1 & $1(100)$ & 0 & \\
\hline Workers' compensation & 2 & $1(50)$ & $1(50)$ & \\
\hline \multicolumn{5}{|l|}{ Working status* } \\
\hline Working & 87 & $53(61)$ & $34(39)$ & \multirow[t]{4}{*}{$<.001$} \\
\hline Unemployed & 3 & $3(100)$ & 0 & \\
\hline Retired & 17 & $17(100)$ & 0 & \\
\hline Disabled & 5 & $2(40)$ & $3(60)$ & \\
\hline \multicolumn{5}{|l|}{ Marital status* } \\
\hline Single & 32 & $17(53)$ & $15(47)$ & \multirow[t]{4}{*}{.041} \\
\hline Married & 69 & $47(68)$ & $22(32)$ & \\
\hline Separated or divorced & 6 & $6(100)$ & 0 & \\
\hline Widowed & 5 & $5(100)$ & 0 & \\
\hline NVS Health Literacy ${ }^{\dagger}$ & $4.6 \pm 1.9(0-6)$ & $4.5 \pm 2.0(0-6)$ & $4.8 \pm 1.7(1-6)$ & .43 \\
\hline \multicolumn{5}{|l|}{ PROMIS instruments ${ }^{\dagger}$} \\
\hline Pain Interference & $59 \pm 8.5(39-76)$ & $59 \pm 8.3(39-76)$ & $59 \pm 8.9(39-74)$ & .93 \\
\hline Upper Extremity Function & $39 \pm 10(16-56)$ & $39 \pm 9.9(22-56)$ & $37 \pm 10(16-56)$ & .29 \\
\hline Depression & $46 \pm 9.0(34-64)$ & $44 \pm 8.6(34-64)$ & $50 \pm 8.6(34-64)$ & $<.001$ \\
\hline Previsit expectation of visit duration $(\mathrm{min})^{\dagger}$ & $16 \pm 9.6(3-60)$ & $16 \pm 11(3-60)$ & $15 \pm 7.0(5-30)$ & .60 \\
\hline \multicolumn{5}{|l|}{ Visit characteristics } \\
\hline Actual waiting time to see surgeon $(\mathrm{min})^{\dagger}$ & $29 \pm 16(5-80)$ & $29 \pm 17(5-80)$ & $31 \pm 15(6-71)$ & .47 \\
\hline Actual visit duration $(\mathrm{min})^{\dagger}$ & $10 \pm 5.6(2-30)$ & $11 \pm 5.7(3-30)$ & $10 \pm 6.3(2-30)$ & .81 \\
\hline \multicolumn{5}{|l|}{ Appointment type* } \\
\hline First opinion & 107 & $72(67)$ & $35(33)$ & \multirow[t]{2}{*}{.73} \\
\hline Second opinion & 5 & $3(60)$ & $2(40)$ & \\
\hline \multicolumn{5}{|l|}{ Resident/fellow involvement* } \\
\hline No & 68 & $43(63)$ & $25(37)$ & \multirow[t]{2}{*}{.30} \\
\hline Yes & 44 & $32(73)$ & $12(27)$ & \\
\hline \multicolumn{5}{|l|}{ Attending surgeon* } \\
\hline A & 75 & $45(60)$ & $30(40)$ & \multirow[t]{2}{*}{.026} \\
\hline All others & 37 & $30(81)$ & $7(19)$ & \\
\hline
\end{tabular}




\section{APPENDIX A. Characteristics of Study Sample (Outcome: Patient Satisfaction) (Continued)}

\section{Patient Satisfaction With Surgeon}

\begin{tabular}{|c|c|c|c|c|}
\hline Parameter & All Patients & Satisfied $(9-10)$ & Dissatisfied $(\leq 8)$ & $P$ \\
\hline \multicolumn{5}{|l|}{ Day of the week } \\
\hline Monday & 41 & $28(68)$ & $13(32)$ & .12 \\
\hline Tuesday & 7 & $7(100)$ & 0 & \\
\hline Wednesday & 42 & $23(55)$ & $19(45)$ & \\
\hline Thursday & 16 & $12(75)$ & $4(25)$ & \\
\hline Friday & 6 & $5(83)$ & $1(17)$ & \\
\hline \multicolumn{5}{|l|}{ Patient perceptions } \\
\hline $\begin{array}{l}\text { Perceived waiting time to see surgeon } \\
\quad(\min )^{\dagger}\end{array}$ & $19 \pm 14(2-90)$ & $18 \pm 14(2-60)$ & $21 \pm 16(2-90)$ & .22 \\
\hline Perceived visit duration $(\min )^{\dagger}$ & $10 \pm 6.0(2-30)$ & $10 \pm 6.0(2-30)$ & $9.2 \pm 5.7(2-30)$ & .28 \\
\hline \multicolumn{5}{|l|}{ Perceived surgeon rush* } \\
\hline No & 100 & $73(73)$ & $27(27)$ & $<.001$ \\
\hline Yes & 12 & $2(17)$ & $10(83)$ & \\
\hline CARE Measure ${ }^{\dagger}$ & $43 \pm 8.0(19-50)$ & $47 \pm 4.9(31-50)$ & $36 \pm 8.0(19-50)$ & $<.001$ \\
\hline \multicolumn{5}{|l|}{ Diagnosis* } \\
\hline Traumatic & 51 & $32(63)$ & $19(37)$ & .39 \\
\hline Nontraumatic & 61 & $43(70)$ & $18(30)$ & \\
\hline
\end{tabular}

CARE, Consultation and Relational Empathy.

*The values are given as the number of patients, with the percentage in parentheses.

$\dagger$ The values are given as the mean and the SD, with the range in parentheses.

$\ddagger$ Bold type indicates statistical significance $(P<.05)$ 
APPENDIX B. Characteristics of Study Sample (Outcome: Patient-Perceived Surgeon Rush)

Patient-Perceived Surgeon Rush

\begin{tabular}{|c|c|c|c|}
\hline \multirow[b]{2}{*}{ Parameter } & & & \multirow[b]{2}{*}{$P$} \\
\hline & Yes & No & \\
\hline Total* & $12(11)$ & $100(89)$ & \\
\hline Age $(y)^{\dagger}$ & $36 \pm 12(24-60)$ & $50 \pm 16(21-88)$ & .0028 \\
\hline \multicolumn{4}{|l|}{ Sex* } \\
\hline Female & $4(7.7)$ & $48(92)$ & \multirow{2}{*}{.34} \\
\hline Male & $8(13)$ & $52(87)$ & \\
\hline \multicolumn{4}{|l|}{ Race/ethnicity* } \\
\hline White & $7(8.6)$ & $74(91)$ & \multirow{2}{*}{.25} \\
\hline Nonwhite & $5(16)$ & $26(84)$ & \\
\hline Education $(y)^{\dagger}$ & $16 \pm 3.3(12-24)$ & $16 \pm 2.8(9-27)$ & .82 \\
\hline \multicolumn{4}{|l|}{ Insurance status* } \\
\hline Medicare & 0 & $15(100)$ & \\
\hline Medicaid & 0 & $3(100)$ & \\
\hline Private & $11(12)$ & 80 & .23 \\
\hline Uninsured & 0 & $1(100)$ & \\
\hline Workers' compensation & $1(50)$ & $1(50)$ & \\
\hline \multicolumn{4}{|l|}{ Working status* } \\
\hline Working & $11(13)$ & $76(87)$ & .35 \\
\hline Unemployed & 0 & $3(100)$ & \\
\hline Retired & 0 & $17(100)$ & \\
\hline Disabled & $1(20)$ & $4(80)$ & \\
\hline \multicolumn{4}{|l|}{ Marital status* } \\
\hline Single & $6(19)$ & $26(81)$ & .24 \\
\hline Married & $6(8.7)$ & $63(91)$ & \\
\hline Separated or divorced & 0 & $6(100)$ & \\
\hline Widowed & 0 & $5(100)$ & \\
\hline NVS Health Literacy ${ }^{\dagger}$ & $5.0 \pm 1.9(1-6)$ & $4.6 \pm 1.9(0-6)$ & .47 \\
\hline \multicolumn{4}{|l|}{ PROMIS instruments ${ }^{\dagger}$} \\
\hline Pain Interference & $60 \pm 9.2(39-70)$ & $59 \pm 8.4(39-76)$ & .80 \\
\hline Upper Extremity Function & $36 \pm 10(22-56)$ & $39 \pm 9.9(16-56)$ & .35 \\
\hline Depression & $46 \pm 7.1(34-57)$ & $46 \pm 9.2(34-64)$ & .91 \\
\hline Previsit expectation of visit duration $(\mathrm{min})^{\dagger}$ & $14 \pm 6.3(5-27)$ & $16 \pm 10(3-60)$ & .40 \\
\hline \multicolumn{4}{|l|}{ Visit characteristics } \\
\hline Actual waiting time to see surgeon $(\mathrm{min})^{\dagger}$ & $27 \pm 12(6-51)$ & $39 \pm 17(5-80)$ & .54 \\
\hline Actual visit duration (min) ${ }^{\dagger}$ & $14 \pm 6.7(5-28)$ & $10 \pm 5.8(2-30)$ & .26 \\
\hline \multicolumn{4}{|l|}{ Appointment type* } \\
\hline First opinion & $10(9.3)$ & $97(91)$ & .088 \\
\hline Second opinion & $2(40)$ & $3(60)$ & \\
\hline \multicolumn{4}{|l|}{ Resident/fellow involvement* } \\
\hline No & $8(12)$ & $60(88)$ & .66 \\
\hline Yes & $4(9.1)$ & $40(91)$ & \\
\hline \multicolumn{4}{|l|}{ Attending surgeon* } \\
\hline A & $9(12)$ & $66(88)$ & .53 \\
\hline All others & $3(8.1)$ & $34(92)$ & \\
\hline
\end{tabular}




\section{APPENDIX B. Characteristics of Study Sample (Outcome: Patient-Perceived Surgeon Rush) (Continued)}

Patient-Perceived Surgeon Rush

\begin{tabular}{|c|c|c|c|}
\hline \multirow[b]{2}{*}{ Parameter } & & \multirow[b]{2}{*}{$P$} \\
\hline & Yes & No & \\
\hline \multicolumn{4}{|l|}{ Day of the week } \\
\hline Monday & $4(9.8)$ & $37(90)$ & .70 \\
\hline Tuesday & 0 & $7(100)$ & \\
\hline Wednesday & $7(17)$ & $35(83)$ & \\
\hline Thursday & $1(6.3)$ & $15(94)$ & \\
\hline Friday & 0 & $6(100)$ & \\
\hline \multicolumn{4}{|l|}{ Patient perceptions } \\
\hline $\begin{array}{l}\text { Perceived waiting time to see surgeon } \\
\quad(\min )^{\dagger}\end{array}$ & $23 \pm 12(5-40)$ & $18 \pm 15(2-90)$ & .27 \\
\hline Perceived visit duration $(\min )^{\dagger}$ & $7.9 \pm 4.9(2-17)$ & $10 \pm 6.1(2-30)$ & .15 \\
\hline CARE Measure $^{\dagger}$ & $34 \pm 7.0(21-40)$ & $44 \pm 7.3(19-50)$ & $<.001$ \\
\hline \multicolumn{4}{|l|}{ Satisfaction with surgeon* } \\
\hline No & $10(27)$ & $27(73)$ & $<.001+$ \\
\hline Yes & $2(2.7)$ & $73(97)$ & \\
\hline \multicolumn{4}{|l|}{ Diagnosis* } \\
\hline Traumatic & $9(18)$ & $42(82)$ & .030 \\
\hline Nontraumatic & $3(4.9)$ & $58(95)$ & \\
\hline
\end{tabular}

CARE, Consultation and Relational Empathy.

*The values are given as the number of patients, with the percentage in parentheses.

$\dagger$ The values are given as the mean and the SD, with the range in parentheses.

$\ddagger$ Bold type indicates statistical significance $(P<.05)$.

\section{APPENDIX C. Multivariable Logistic Regression:}

Factors Associated With Patient Perception of

Surgeon Rush*

\begin{tabular}{ccccc} 
& & \multicolumn{3}{c}{$95 \% \mathrm{CI}$} \\
\cline { 3 - 4 } Predictor & OR & Lower & Upper & $P$ \\
\hline $\begin{array}{c}\text { Age, per 10-y } \\
\text { increase }\end{array}$ & 0.69 & 0.41 & 1.2 & .16 \\
$\begin{array}{c}\text { CARE Measure, per } \\
\quad \text { 1-unit increase }\end{array}$ & 0.86 & 0.79 & 0.94 & $\mathbf{. 0 0 1}^{\dagger}$ \\
$\begin{array}{c}\text { Traumatic injury } \\
\text { (reference: } \\
\text { nontrauma) }\end{array}$ & 2.7 & 0.55 & 13 & .22 \\
\hline
\end{tabular}

CARE, Consultation and Relational Empathy.

$*$ Nagelkerke $\mathrm{R}^{2}=0.371 ; P$ value for the Hosmer-Lemeshow test $=.666$.

$\dagger$ Bold type indicates statistical significance $(P<.05)$. 